\title{
A Study on Evaluation Factors and Approaches Of Professional Moral Education For High Occupational Students
}

\author{
Pan Xiaoyan \\ Beijing Polytechnic, No.9 Street 1, Liangshuihe, Development Area, Beijing, China \\ Panxiaoyan818@126.com
}

\begin{abstract}
Keywords: High occupational; professional moral education; evaluation factor; evaluation approach
\end{abstract}

Abstract. The poor professional moral level of high occupational students affects students' development, reform and innovation of occupational education, and the construction of modern occupational education system. How to determine the professional moral evaluation factors and build up comprehensive and objective evaluation approaches for high occupational students has been an urgent problem to strengthen the professional moral education for high occupational students.

High occupational education, as a type of higher education, has gained great support from the government and achieved rapid growth, cultivating millions of quality professionals. As China is now in its crucial time to build up a moderately prosperous society in an all-round way and in its critical juncture to deepen its reform and opening up, and to accelerate its transformation of economic growth patterns, various industries in China are undergoing a rapid development, which demands higher quality occupational students. However, in terms of professional moral level, high occupational students cannot meet the requirements to promote occupational education reform and innovation, to build up modern professional education system, and to contribute to national economic and social development and modernization drive. The poor level of professional moral has a direct impact on students' development. Therefore, while attaching great importance to developing students' professional skills, occupational colleges should also make efforts to strengthen students' professional moral education by improving the evaluation factors and approach.

I. Problems on Professional Moral Evaluation Factors and Approaches for High Occupational Students.

With the aim to have a further scientific knowledge of current professional moral education for high occupational students in an all-round way, and to encourage the students to come up with effective comments and suggestions, the author chose 6 different kinds of questionnaire respondents relevant with high occupational education, including heads of 4 colleges, faculty members, employees, occupational education researchers and intermediary agents, high occupational students, and students' parents. Of 900 questionnaires of two different kinds, 883 returned ones are effective, with an effective rate of $98.1 \%$. By analyzing the returned questionnaires, the author finds many problems on the evaluation factors and approaches of high occupational students' professional moral education, directly affecting the comprehensive and scientific implementation of high occupational students' professional moral education. 
1. Problems on evaluation factors of professional moral education for high occupational students

\subsection{Incomprehensive Evaluation Factors}

By analyzing the returned questionnaires and comments from different subjects, especially the suggestions from personnel in occupational research institutions, the author finds the evaluation factors of professional moral education for high occupational students are not comprehensive. Some factors, such as "the influence of campus culture", "network building of professional moral education in colleges", "evaluations from employers”, which are rarely seen in evaluation system, have been applied and have played an important role in the professional moral education for high occupational students. Thus, to deepen the professional moral education, we need to take various influence factors into account, enrich and improve evaluation factors to build a more integrated evaluation system.

\subsection{Less objective and scientific weight determination of evaluation factors}

Through research and analysis, the author finds the current applied evaluation approaches are lack of proper weight determination of evaluation factors, which means lack of importance differences between various factors. The scores are just equally distributed with the lack of objectivity. Besides, according to the statistics from the questionnaires, the author finds, of 17 factors involved in the professional moral education, the score gap is 11.7 between the factor with highest score and that with the lowest. Most of questionnaire respondents believe that the importance between factors differentiate in the evaluation system, and should be shown through weights, which can show the importance of evaluation factors and can improve the evaluation results.

1.3 The implications of evaluation factors are not clear

Evaluation factors are often classified into two grades in the evaluation system. The first-class factors are usually summarized by a few words, and the second-class factors are often descriptions with a few more words on the basis of the first-class ones.

2. Problems on evaluation approaches of professional moral education for high occupational students

2.1 Qualitative evaluation is more applied than quantitative evaluation

According to research and statistics, the two main approaches applied to the evaluation of professional moral education are qualitative and quantitative evaluation. In some evaluation system of professional moral education in a high occupational college, 10 of its evaluation factors are mainly qualitative evaluation on "importance" attached on professional moral education; and the other 9 factors are mainly quantitative evaluation. Therefore, we can see that now the qualitative evaluation is more applied than quantitative evaluation, which reflects the lack of scientific quantitative index, poor operability and feasibility. 
Through research and analysis, the author finds many people assessed in evaluation system of occupational professional moral education, participate in rating themselves, which will reduce the objectivity due to the subjective judges. Besides, the questionnaire evaluation approach also has some problems, such as the simple methods of data collection and analysis, lack of diversity of subjects and discordance between questionnaire contents and evaluation factors, which will affect the objectivity in questions design and data collection. And as to qualitative assessment, the assessment is out of evaluation subjects' experience, the past and current situation of occupational professional moral education, and some relevant materials. These kinds of evaluation are usually very subjective, reflecting the attitude of evaluation subjects, which will lead to a less objective and less scientific evaluation.

\subsection{Lack of diversity of evaluation subjects and evaluation approaches}

Through research and analysis, the author finds the evaluation approaches are lack of diversity, with too much attention on education results while neglecting the evaluation of professional moral activities and education process. Besides, the backgrounds of evaluation subjects are lack of diversity either, with too much attention on the colleges or educational departments while neglecting the evaluation research institutions of professional education, students, employers and parents. Moreover, the current professional moral evaluation is mainly in written form, which makes the evaluation become a test of knowledge instead of assessment of capacity and behavior; the evaluation system is also with too much attention to assessment given by professional moral teachers or college counselors while with less attention to the integrated assessment from other teachers, and with more attention to educators' evaluation while with less to the students'. So the existent evaluation approach can hardly reflect the actual situation and level of professional moral education, and there may be great different evaluation results between colleges and society as well as employers, which can have a direct impact on the further development of professional moral education.

II. Suggestions for improving evaluation factors and approaches of professional moral education for high occupational students

The professional moral education for high occupational students has both explicit and implicit progress, which is the process of students' internalization and externalization. The gradual effects of professional moral education and other relevant education determine the evaluation of professional moral education as a complex problem. Through the research and analysis of professional moral education for high occupational students, and to address the existent problems in evaluation factors and approach, the author propose the suggestions as follows:

\section{Determine the evaluation factors and its weights in a scientific way}

\subsection{Determine the evaluation factors objectively and comprehensively}

With the rapid growth of China's high occupational education, occupational education is gaining increasing attention. The number of people contributed to the occupational education has also been increasing with more diversity. That's the reason why we need to integrate more various factors into the evaluation system, with the aim to present the professional moral education for high 
occupational students comprehensively and objectively, and to discover the problems that needs correcting.

Besides, the influences of evaluation factors vary from college to college due to their various financial conditions and college locations. As a result, we need to divide the factors into different modules, determine its classifications and applying range to have a detailed picture of professional moral education in different colleges and their students’ professional moral conditions.

\subsection{Determine the factors' weights scientifically and reasonably}

When the evaluation system is set up, evaluation factors with different importance will be included. The importance differences are not subject to one's opinion, which can only be determined through quantitative calculation and analysis. Therefore, when the index factors are determined, we should distribute proper weights to each factor, which we can get from the calculation and analysis of the research data. The determination of evaluation factors should be both reasonable and scientific.

2. Diversified evaluation approaches should be applied to the professional moral education evaluation for high occupational students.

\subsection{The diversification of evaluation subjects}

As high occupational education gains more and more attention and high occupational students are high quality personnel cultivated specifically for the frontline of service or production, the education and cultivation for students should be accord with companies' production needs, and at the same time, with the social and economic development. Meanwhile, the relevant entities are increasing, so we should attract them to the evaluation to have more diverse evaluation subjects to reflect objective situation of professional moral education for high occupational students. And in the process of evaluation, different evaluation subjects can be invited according to actual situation, and number of evaluation subjects should meet some specific standard to ensure the objectivity of the results.

\subsection{The diversification of evaluation approaches}

As there are a number of evaluation factors, different factors' weights, and the diversification of evaluation subjects in the evaluation, different evaluation approaches should be specified according to the facts, for example, the combination of "direct rating" and "evaluation through questionnaires", and the combination of "quantitative evaluation" and "qualitative evaluation". The factors, which cannot be directly quantified, can be indirectly quantified. And applying qualitative evaluation in the quantitative analysis will improve the clearer implication of quantitative index. Besides, the presentation of evaluation results should also be in an integrated way, instead of measuring the results only by scores. Spider diagram and scatter gram can also be used to make up an objective and visible results presentation with both factor scores in different classifications, and with an integrated picture.

In conclusion, a comprehensive and scientific evaluation system and approaches of professional moral education for high occupational students should be established with reasonable determination of factors, weights and quantitative indexes, with the aim to address the problems emerged in the 
evaluation, which can promote students' capacity, professional moral education in high occupational colleges, and the advancement of the colleges.

\section{References}

[1] Ministry of Education of the People's Republic of China: Employment-oriented Thoughts on Deepening High Occupational Education Reforms (2004)

[2] Ministry of Education and Ministry of Finance of the People's Republic of China: On Supporting High Occupational Colleges to Enhance the Professional Development Capacity of the Service Industry (2011).

[3] Wang Xiangang: A Study on the Professional Moral Quality Promotion of High Occupational Students, (Faculty Forum, China, 2004).

[4] Zheng Feng: Study on Professional Moral Problems and its Causes for High Occupational Students (Journal of Lanzhou Institute of Education, China, 2000).

[5] QiuYongfei, Chen Hong: A Research Overview on Professional Moral Education of High Occupational Students (Journal of Xinyu College, 2013) 